\title{
Total Retention Liquid Chromatography-Mass Spectrometry to Achieve Maximum Protein Sequence Coverage
}

\author{
Mark E. Jennings, II,,$\|$ Jay R. Silveira, ${ }^{\ddagger}$ Kimberly M. Treier,,$\stackrel{\perp}{ }$ Paula B. Tracy,$\star$ Dwight E. \\ Matthews $*, \dagger, \S$ \\ Departments of ${ }^{\dagger}$ Medicine, ${ }^{\star}$ Biochemistry, and ${ }^{\S}$ Chemistry, University of Vermont, Burlington, \\ VT 05405 United States
}

\section{Supporting Information}

\section{Contents:}

Table S-1. Neutral-loss mass list used for selecting the site-specific glycoprofiling

Table S-2. Hydrophobicity indices for the peptides shown in Figure 3 
Table S-1. Neutral-loss mass list used for selecting site-specific glycoprofiling

\begin{tabular}{|c|c|c|c|}
\hline \multicolumn{2}{|c|}{ Sugar } & \multicolumn{2}{c|}{ m/z loss } \\
\hline Name (Abbreviation) & MW & $\mathbf{z = 2}$ & $\mathbf{z}=\mathbf{3}$ \\
\hline Fucose (Fuc) & 146.1 & 73.1 & 48.7 \\
Hexose (Hex) & 162.1 & 81.1 & 54.0 \\
N-Acetyl Hexosamine & 203.2 & 101.6 & 67.7 \\
(HexNAc) & 291.3 & 145.7 & 97.1 \\
Sialic Acid (SA) & 365.3 & 182.7 & 121.7 \\
N-Acetyl Hexosamine & & & \\
Hexose (HexNAcHex) & & & \\
\hline
\end{tabular}

Table S-2. Hydrophobicity indices for the peptides shown in Figure 3

\begin{tabular}{|c|r|}
\hline Peptide & $\begin{array}{c}\text { Hydrophobicity } \\
\text { index }\end{array}$ \\
\hline Region 1: & -2.42 \\
\hline DVK & -4.34 \\
\hline SSSSGK & -5.52 \\
\hline SSSSGKK & 1.76 \\
\hline Region 3: & 1.08 \\
\hline TLVR & 5.18 \\
\hline STNFK & 4.50 \\
\hline DVFGK &
\end{tabular}

*The theoretical hydrophobicity index of each peptide was calculated using SSRCalc (http://hs2.proteome.ca/SSRCalc/SSRCalcQ.html). We choose the C18 and $0.1 \%$ formic acid setting in the calculator; there is no C8 option. Negative values indicate low hydrophobicity (high hydrophilicity); positive values indicate increasing hydrophobicity. 